\title{
Economics of human performance and systems total ownership cost ${ }^{1}$
}

\author{
Wilawan Onkham*, Waldemar Karwowski, and Tareq Z. Ahram \\ Institute for Advance System Engineering, Department of Industrial Engineering and Management Systems, \\ University of Central Florida, Orlando, FL 32816, USA
}

\begin{abstract}
Financial costs of investing in people is associated with training, acquisition, recruiting, and resolving human errors have a significant impact on increased total ownership costs. These costs can also affect the exaggerate budgets and delayed schedules. The study of human performance economical assessment in the system acquisition process enhances the visibility of hidden cost drivers which support program management informed decisions. This paper presents the literature review of human total ownership cost (HTOC) and cost impacts on overall system performance. Economic value assessment models such as cost benefit analysis, risk-cost tradeoff analysis, expected value of utility function analysis (EV), growth readiness matrix, multi-attribute utility technique, and multi-regressions model were introduced to reflect the HTOC and human performancetechnology tradeoffs in terms of the dollar value. The human total ownership regression model introduces to address the influencing human performance cost component measurement. Results from this study will increase understanding of relevant cost drivers in the system acquisition process over the long term.
\end{abstract}

Keywords: Human Performance Estimation, Human Total Ownership Cost

\section{Introduction}

During economic recession, cost estimation becomes one of the most important tasks in managing both government agencies and businesses funds. Organizations generally try to minimize running costs and maximize their performance and return on investment [ HYPERLINK $\backslash 1$ "Ahr9b" 1 ]. Total ownership cost (TOC) is defined as the actual costs associated with business during operation2]\}. It is also explained as the overall costs of the entire life cycle of a system [ HYPERLINK $\backslash 1$ "Bou" 3 ]. In terms of government perspective, Gansler (1998) 4] \} described that "TOC is the sum of all financial resources necessary to organize, equip, train, sustain, and operate military forces sufficient to meet national goals in compliance with all laws, all policies applicable to DoD, all standards in effect for readiness, safety, and quality of life, and all other official measures of performance for DoD and its components. DoD TOC is comprised of [sic] costs to research, develop, acquire, own, operate, and dispose of weapon and support systems, other equipment and

${ }^{1}$ Economics of Human Performance and Systems Total Ownership Cost

* Wilawan onkham, Waldemar Karwowski, and Tareq Z. Ahram are with Institute for Advance System Engineering, Department of Industrial Engineering and Management Systems, University of Central Florida, Orlando, FL 32816, USA. E-mail: owilawan@knights.ucf.edu\} ; wkar@ucf.edu; tahram@ucf.edu. real property, the costs to recruit, train, retain, separate and otherwise support military and civilian personnel, and all other costs of business operations of the DoD”. TOC metrics show the actual expenditures and comparison of future cost planning. It is used in identifying the sorted list of high cost drivers and for managing system TOC to forecast the budget which can support decision making in high-level management [ HYPERLINK $\backslash 1$ "Hit98" 2 ].

According to USAF, all high costs are not due to hardware, but are associated with training costs and changes in policies, processes and procedures. One automobile manufacturer found a seven-track methodology (people, organizational systems, processes, work environment, skill/knowledge, job aids/tools, products and supporting technology) in addition to training employee held solutions for complex human and technology performance issues. Employees were able to leverage the value of technology, but the cost of training and maintaining personnel skills were higher than their expectations. 
As a result, organizations attempt to maximize the value of total technology-human asset infrastructure in order to reduce cost in the long term [5].

Hoffman [6] has defined acquisition costs are the exaggerated cost at the expenditure of lifecycle costs where products are designed and developed. The decision makers should carefully consider the total ownership cost (TOC). The cognitive tendencies are over emphasized on acquisition costs which are frequently driven by production misalignment and limited evaluation on the design decisions during lifecycle costs. As a result, delivering the asset or products drive the higher TOC. Additionally, the technology and functionality decisions are made with incomplete insight of cost implications, and biased procurement decisions that have negative impact on the entire of system. There are several constraints that add to the difficulty of quantifying the effect of design decisions on TOC. These include undefined boundaries analysis, soft cost driver factors (human value, nonlinear relationship and second order impact), inconsistent data, management accounting and unknowns influenced by technology and applications including underestimated costs. The misidentification of human cost has negative impacts on the system design, training, recruiting and mission-goal achievement; consequently, the total of system performance decreases dynamically over time $[6,7]$.

Hoffman [8] stated that misestimating of the human factors impact costs increase the rate of software procurement failure and slipped schedule. The statistics specified a miserable record, showing the expenditure of billions of dollars for technologies that are ineffective and insufficient and at times unable to perform the task.

As a result, human factors need to be addressed to some degree to achieve the specific process needs which can support to produce the desired outputs focusing on costs associated with human factors (human capability, human reliability, decision making) in terms of human performance in order to reduce the risk and uncertainty and total ownership cost for the long run. The total ownership cost should contain not only the product life cycle cost, training cost and cost of technology but also of human characteristic impact cost. Integrating the knowledge of economics, human factors and system engineering aspects to identify the hidden costs associated with human performance will gain understanding on human total ownership cost (HTOC). Establishing the human total ownership cost measurement and metrics will benefit the organization in decision making and prevention of system failure.

This paper is organized as follows. First, the background and literature summary of studies on human total ownership cost (HTOC) are represented. The scope of the HTOC and what it should consist of are specified. Second, the economic assessment value model (EAV) is articulated. The economic model addresses associated costs to achieve the targeted human performance which will reflect HTOC in term of dollars. Finally, the multi-regression of HTOC is illustrated based on human performance influencing factors involving human factor impact, task complexity, human error, information, training, recruiting and environment factors impact. The EAV will be the solution approach for capturing the entire system which provides better visibility of hidden costs for the decision maker.

\section{Background and literature summary}

Traditionally, human resource accounting (HRA) is employed to quantify the economic value of people and measure the intellectual asset in order to provide information and data for corporate management level [9]. Three types of HRA measurement models are commonly implemented in service organizations which are: cost models, HR value models and monetary models. However, there is no evidence to support the long term success of these models [10]. Researchers have proposed several tools and models to quantify the human cost. Those models are still questionable in validity, reliability and generalizability.

The human total ownership cost (HTOC) is introduced and described as associated with the total ownership cost involving the cost of acquisition, staffing, training cost, re-training cost, cost of recruiting, salary during training, cost of training support and cost of human error (error frequency average costs as a percentage of revenue). Costs increase upon initial cognitive systems engineering activities in the design and development phase [6]. Zachary [11] has defined that human costs are initiated or exacerbated by user-centered design approaches. Cognitive task analysis is determined as an extraneous variable. It is indicated as a weak procedure and executed at project outset as a one-off activity. HTOC should include the cost of retaining, cost of training, cost of recruiting, and training additional 
people to replace the trainees who leave. As a result, the inadequate cost estimation and inappropriate decisions in the initial phase have a negative impact on the entire organization.

Hoffman [6] defined the HTOC as the associated costs with the procurement from the beginning of technology development projects to human system integration (cognitive engineering). Quantification of HTOC should concern 1) content quality and efficacy 2) communication effectiveness 3) risk management and 4) traceability. HTOC and cognitive engineering should be generalized into the large-scale organization. HTOC should consider safety aspects (system safety and battlefield survivability), readiness (readiness performance on mission) and mission success (the probability to complete the mission/project). However, these elements may be difficult to measure in both of conception and practice. While, Burns also identified the challenge for human factors in system acquisition particularly the life cycle sustainment outcome metrics. Essentially, HTOC has directly influenced into the human performance as the outcome of system design.

The National Air-space System (NAS) modernization program has attempted to develop decision support tools (e.g. traffic management advisor), changing procedural, and process to improve software/hardware and advance technology. All these missions directly affect both of operational users and maintenance staff. As a result, the user needs, their characteristics and human factor costs are considered for all programs. They also specify the 18 relevant cost components regarding human factors including 1) designer cost, 2) programmer cost, 3) human factor staff cost, 4) laboratory cost, 5) participant cost, 6) subject matter expert cost, 7) user needs assessment cost, 8) concept studies cost, 9) prototype and usability assessment costs, 10) modeling and fasttime simulations cost, 11) real-time human-in-theloop simulation cost, 12) experiment/study plan development cost, 13) scenario development cost, 14) scenarios shakedown cost, 15) final simulation cost, 16) data collection cost, 17) data analysis cost, and 18) final report development cost. They introduced three different human factors cost estimation approaches as follow [12]:

- Expert judgment approach (cost estimation committee)

- Parametric cost estimation approach (based on type of human factor impact, type of studies)

\section{- Cost estimation based on a heuristics approach}

The impacts of HTOC on design and procurement were articulated in Table 1. HTOC analysis must be completed in initial phase of product life cycle in order to reduce the uncertainty of TOC for the entire system even though measuring the human total ownership cost involves the high degree of complexity and qualitative factors.

Typically, the economic value of intelligence is the dollar premium that a business is willing to pay for intelligence where a financial performance is metric for intelligence employees within the context of the job at hand [13]. Therefore, HTOC can be determined as the willingness to pay on the human for enhancing one unit of human performance during operation. Estimating the HTOC can provide the visibility into cost drivers associated with human performance which is useful to manage the budget and support making decisions to make the right decision in right time with right input.

However, the study on HTOC and measurement need the empirical data, historical database, and various parameters of element acquisition which may seem expensive in the initial phase, but the knowledge and data from estimating costs and human performance would be of benefit for budget management, alternative selection of technology, monitoring performance during the operation process, simulating the feasible maintenance solution and balancing of capabilities and affordability. The economic value assessment models (i.e. cost effectiveness analysis, cost benefit analysis, risk-cost trade-off analysis, expected value of utility function analysis, growth readiness matrix, multi-regression model) are initially good tools and techniques to quantify human total ownership cost.

\section{Economic assessment value model (EAV)}

Several economic models and techniques have been developed to assess the benefit and cost for supporting the decision makers and quantifying the uncertainty and level of technology. Although HTOC is difficult to quantify in term of monetary value, particularly the human factors impact costs such as cognition, physical, sensory, perceptual and skill, the authors attempt to find the appropriate economic model of human total ownership cost involving cost 
effective analysis (CEA), cost benefit analysis (CBA), risk-cost tradeoff analysis, expected value of utility function analysis $(\mathrm{EV})$, growth readiness matrix and multi-regression model to reflect human-value, technology tradeoffs and human performance in term of dollar value.

Table 1: The impact of human cost of ownership on design and procurement

(Adapted from Hoffman [6])

\begin{tabular}{|l|l|l|}
\hline Human Factor & Design problems & Financial footprint, longer-term impact \\
\hline Training & Poor designs are harder to learn & $\begin{array}{l}\text { Training takes longer and might increase } \\
\text { wash-outs, both of which increase costs }\end{array}$ \\
\hline Recruitment & $\begin{array}{l}\text { User frustration and training wash-outs means more recruit- } \\
\text { ment }\end{array}$ & $\begin{array}{l}\text { Recruitment become more difficult and } \\
\text { takes longer, costing more }\end{array}$ \\
\hline Frustration & $\begin{array}{l}\text { People's engagement with their work is decreased by tools that } \\
\text { are not usable, useful and understandable }\end{array}$ & $\begin{array}{l}\text { Work output falls and work attrition in- } \\
\text { creases, leading to need for more people to } \\
\text { maintain productivity(attendant costs) }\end{array}$ \\
\hline Performance cost & Poor designs increase errors of various kinds & $\begin{array}{l}\text { Error mitigation costs accumulate and } \\
\text { increase }\end{array}$ \\
\hline Opportunity cost & $\begin{array}{l}\text { Longer training, recruitment processes result in positions going } \\
\text { unfilled for longer times }\end{array}$ & $\begin{array}{l}\text { Mission goals and customer needs aren't } \\
\text { achieved; competitors might benefit }\end{array}$ \\
\hline Reliability cost & Increased reliability reduces human total ownership cost & $\begin{array}{l}\text { The higher the human reliability the better } \\
\text { the overall performance and the lower the } \\
\text { total ownership cost spending }\end{array}$ \\
\hline
\end{tabular}

\subsection{Cost Benefits Analysis (CBA)}

Cost benefit analysis (CBA) is used to compare the benefits and losses associated with different options. The relevant factors have to be expressed in monetary terms. It is implemented within many problems especially for minimizing total cost and cost comparison. Whalen [13] suggested that an intelligent constructed system must provide a better cost/benefit ratio than any combination of human being(s) and unintelligent constructed system(s). The best cost/benefit ratio is not necessarily the smartest one, but it will be the system-human integration that maximizes performance. As a result, this analysis can be applied to evaluate and quantify HTOC in terms of 1) Cost of technology vs. human performance and cost of technology vs. learning curve 2) Cost of technology vs. risk reduction, 3) Cost of training vs. human performance, and 4) Associated costs on human performance (training, technology, information, safety (T2IS) and system readiness). The example of reduction in total ownership cost (R-TOC) by using the CBA with the expected net benefit per dollar of investment is illustrated in Figure 1 [14].

Boudreau [3] also used the CBA for reduction in total ownership cost within military. The result shows the effectively reducing TOC and increasing the warfighter's capabilities when the funding is adequately provided in acquisition phase or in the operation system phase. Figure 2 illustrates the sample of
CBA between the human performance and cost of technology and learning curve regarding HTOC.

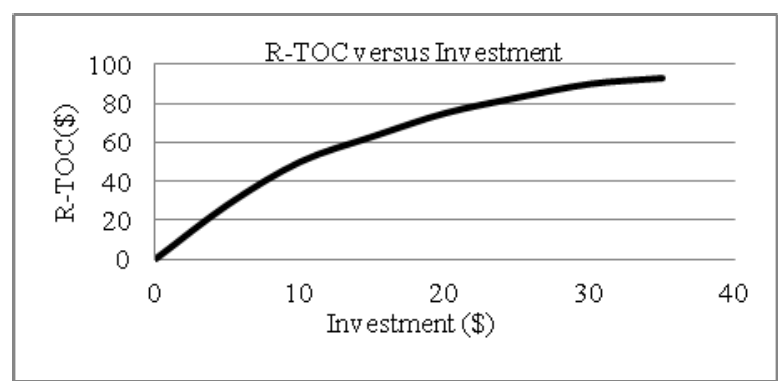

Fig. 1: The cost benefit analysis between R-TOC and Investment (Adapted from [14])

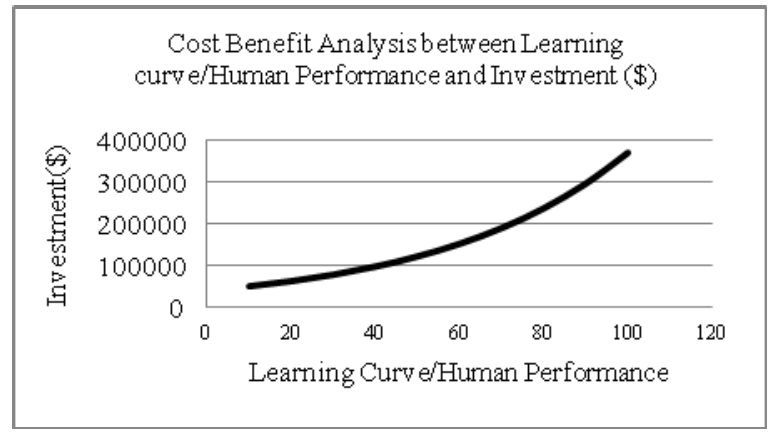

Fig. 2: The Example of cost benefit analysis conducted to assess human performance in technology learning curve versus investment. 


\subsection{Risk-cost trade-off analysis}

Risk-cost tradeoff analysis is used to assess the risk and relevant costs associated with various technology platforms which related to human performance requirements. It is explained as one unit of human performance improvement is compared with the increase in marginal cost. The cost-performance integrated product teams (CPIPTs) is one application of trade-offs analysis that reflects the reduction TOC, performance, and cost. CPIPTs illustrate reducing TOC at the price of reduced performance and system TOC. For instance, a high-maintenance, lowavailability, and cutting-edge system may be tradedoff to a future renovation, technology maturity, system reliability improvement, and ultimately life cycle cost will be reduced. While schedule trade-offs in technology refers to increase test and evaluation, integrate critical software function, and eliminate frustrating downtime and costly maintenance which finally can reduce TOC and increase overall performance [3].

However, it is difficult to quantify the actual relationship for various interventions with the realistic situation, and how the management system enhances the relationships. The sample of this technique can be illustrated to quantify the cost of technology against human performance in Figure 3.

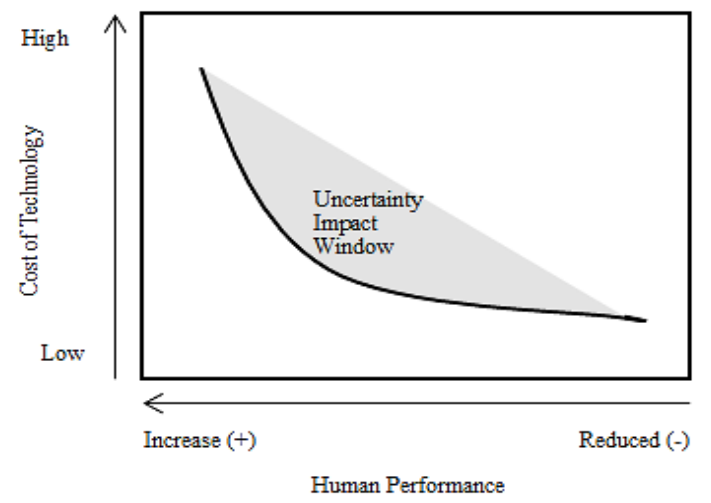

Fig.3: Human performance-cost of technology trade-off curve

\subsection{Expected Value of Utility Function Analysis (EV)}

The expected value (EV) of utility function analysis is applied in many situations, particularly decision making on multiple alternative projects, and when the results of a risk assessment and cost-benefit analysis show the high degree of uncertainty [15]. It offers a better visibility for forecasting the budget.

Abbas [16] illustrates the application of the mathematical model of expected utility which is used for reduction TOC and also shown in equation (1). The example is explained as the engineering department have reduced the future total ownership cost contributions $(\mathrm{C})$ of components subjected to one project by factor $r$ on average $(\mathrm{C} 1=\mathrm{C} 0 / r)$. The proportions of components are assumed to offer significant R-TCO (reduction of total cost of ownership) by factors $p$. As a result, the expected value of perfect information (EVPI) is indicated as the difference between the expected value of the reduction in TCO (EV) (equation 2) and expected value given perfect information (EV $\mid \mathrm{PI})$ (equation 3). The EVPI is shown in equation (4).

$$
\begin{aligned}
& U(x)=\text { Expected Utility } \\
& =\int_{-\infty}^{m} U(x) f(x) d x \\
& \mathrm{EV}=(\mathrm{C}-\mathrm{C} / \mathrm{r}) / \mathrm{p} \\
& \mathrm{EV} \mid \mathrm{PI}=(\mathrm{C}-\mathrm{C} / \mathrm{r}) \\
& \mathrm{EVPI}=(\mathrm{EV} \mid \mathrm{PI})-\mathrm{EV}=\mathrm{C}(1-1 / \mathrm{r})(1-\mathrm{p}) \quad \mathrm{Eq} .(4)
\end{aligned}
$$

Where;

$\mathrm{U}(\mathrm{X})=$ decision-maker's expected utility

$\mathrm{EV}=$ Expected value of the reduction in TCO

EV | PI = Expected value given perfect information

EVPI $=$ Expected value of perfect information

$\mathrm{C}=$ Future total cost of ownership contributions

$r=$ Factor of components subjected to one projects

$p=$ Proportion of components of R-TCO (reduction of total cost of ownership)

\subsection{Growth Readiness Matrix}

The growth readiness matrix captures the basic features of human performance typology. If the organization's goal is enhancing performance and accomplishing growth expectations, this matrix is applied to measure availability or obtainability of human resources skills, styles and experience needed for strategy implementation. The high growth expectation shows the high performance of total system in organization not only hard systems but also the soft systems. Readiness is identified as a proxy for implementation feasibility and indicated as how well resources meet the adequate requirements of the situation. The readiness matrix contains four quadrants; each quadrant represents consist of the limited re- 
sources. The matrix is shown in Figure 4 [17]. This matrix is benefit for monitoring the entire of system performance as well human performance. It can help decision maker to decide whether to invest or expand research and development in order to accomplish their goals.

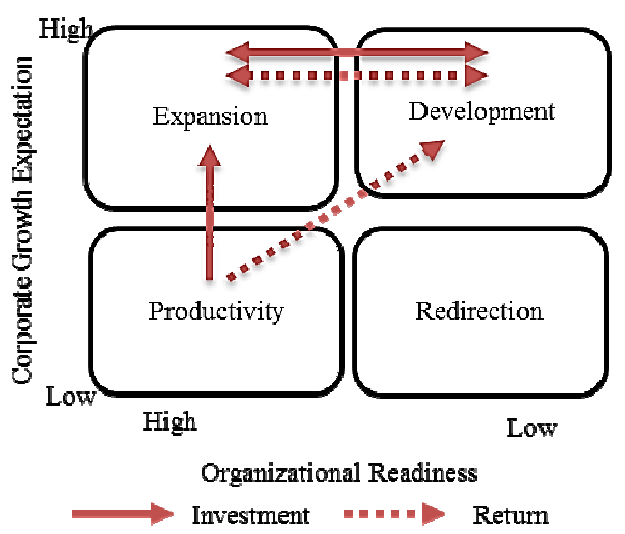

Fig. 4: Growth Readiness Matrix (Adapted from: Lengnick-hall, 1988 [17])

\section{Quadrant 1: Development}

The development quadrant indicates the need for high growth expectations and a low level of organization readiness between strategy and human resource skills. Organizations have few alternative options: 1) Invest in human resources to improve feasibility such as re-training employee after acquisition phase, 2) Change missions to reflect the lack of readiness such as focus on the growth to cost reduction after economic recession, 3) Change the corporate operating strategy to capitalize on the skills and available resources, 4) Maintain the growth missions by altering the competitive advantage used to accomplish missions such as training employee and implementing more technologies.

\section{Quadrant 2: Expansion}

Expansion illustrates the high growth expectations and high level of organization readiness in both of strategy and human resource skills. Human performance expansion depends on: 1) Level of human resource investment required to maintain desired growth and continued readiness, 2) Profitability, and 3) Performance measurement. Since organizational expansion is continuously growing; the organization should be able to maintain the effect of growth such as updating planning systems, managing information, socializing new employee, re-training employee. The organization should identify associated costs of supporting human resource such as technology investment and training in order to improve employee skills and performance.

\section{Quadrant 3: Productivity}

The productivity shows the low growth expectations and high level of organization readiness for strategy and human resources. This situation does not reflect organizational interest in expanding; therefore, operations are highly effective and efficient. If the organizations want to achieve the higher growth expectation, they must invest to increase their growth. Organizations need research and development sector and an extensive environment analysis when they have challenged with high competitions in market.

\section{Quadrant 4: Redirection}

The redirection shows the low growth expectations and low level of organization readiness for strategy and human resources. It indicates that the organization is facing declined market, outdated products and reduced manufacturing process. They emphasize excessive fit between skills, culture, procedures and strategy. Consequently, products have to exit from the market. They must change the direction whether by focusing on readiness activities or by modifying organizational mission.

\subsection{Multi-attribute Utility Technique (MAUT)}

Fulop [18] described that Multi-attribute Utility Technique (MAUT) is the use of utility functions which can be applied to determine the performance values of the alternatives scenarios against the criteria in both of factual (objective, quantitative) and judgmental (subjective, qualitative), to the total utility value with dimensionless. MAUT is to define a scoring scheme (or a multi-attribute utility function). It measures on a weight between 0 and 1 , with the property that if the score (or utility) is the same for two options ( $i$ and $j$ ); there is no preference for one or the other. If the utility for option $i$ exceeds that for option $j$, then option $i$ is preferred to option $j$. To determine the utility value, the simple multi-attribute rating technique (SMART) is formula of MAUT method which is illustrated in equation 5 . 
This technique is recognized for each relevant factor (or attribute) and then aggregates in a total utility function representing the global interest for each option. For example, the estimating utility function between cost minimization against the choice of technology, the result of the highest utility values for the lower cost values represents the best alternative technology. The MAUT is an interesting decision analysis model for high level strategy problems involving different factors (quantitatively or qualitatively).

$$
x_{j}=\Sigma_{\mathrm{j}=1} w_{j} \alpha_{i j} j=1 \quad \text { Eq. (5) }
$$

Where,

- $\mathrm{x}_{\mathrm{j}}=$ Utility value

- $\mathrm{w}_{\mathrm{j}}=$ weight of criteria

- $\mathrm{a}_{\mathrm{ij}}=$ alternative value in the matrix

\subsection{Multi-Regressions Models}

HTOC involves the high degree of complex and subjectively factors. Therefore, measuring HTOC may not be the universal model to implement all organization needs. Instead, the multi-regression model can be conducted upon organization objectives. This regression model reflects the preliminary of HTOC as dependent variable, and the independent variables are considered human performance associated costs based on our literature reviews including human factor-cognition (HFC), human factor-physical (HFP), task complexity (TC), training $(\mathrm{T})$, recruiting(R), retain(RT), skill and knowledge (SK), human reliability (i.e. stress, fatigue, sleep deprivation-HR), risk and uncertainty(RU), technology development (TD), and environment factors(i.e. safety, work domain $\mathrm{EF})$.The regression model is shown in equation (6).

$$
\begin{aligned}
\text { Estimated HTOC }= & b_{0}+b_{1} X 1+b_{2} X 2+b_{3} X 3 \\
& +b_{4} X 4+b_{5} \times 5+b_{6} X 6 \\
& +b_{7} X 7+b_{8} \times 8+b_{9} X 9 \\
& +b_{10} \times 10+b_{11} \times 11+\varepsilon \text { I Eq. (6) }
\end{aligned}
$$

Where; b0, b1, b2 ... $b_{11}$ represents the weight of each component of HTOC and

- $\mathrm{X} 1=$ Number of index of human factorcognition (HFC) functions used for certain task

- $\mathrm{X} 2=$ Number of index of human factor-physical (HFP) functions used for certain task

- $\mathrm{X} 3=$ Number of task (TC)

- $\mathrm{X} 4=$ Number of hours of training (T)

- $\mathrm{X} 5=$ Number of manpower during recruiting(R)
- $\mathrm{X} 6=$ Number of hours to retain (RT) and maintenance

- $\quad \mathrm{X} 7=$ Number of experience years of manpowerskill and knowledge (SK) level

- $\mathrm{X} 8=$ Number of human error during task performing-human reliability(HR)

- $\mathrm{X} 9=$ Number of hours of system downtime as risk and uncertainty(RU),

- $\mathrm{X} 10=$ Number of technology and equipment used during task performing as technology development (TD)

- $\quad \mathrm{X} 11=$ Number of safety equipment-environment factors(EF)

- $\varepsilon I$ represents the substitute of error and uncertainty

\section{Conclusion}

This paper illustrates the background and literature summary related to human total ownership cost (HTOC) and the economic assessment value models (EAV). HTOC is defined as associated with cost of acquisition, staffing, training cost, retain human performance, added capability, cost of recruiting, support and cost of human error. It is useful to provide the visibility into hidden cost drivers and human cost components which can support the budget management and making timely decision for high level management. Misestimating HTOC has significant impact on human performance, design, procurement and long term investment. The high costs in the operational phase are due to human aspect and rise upon continual increase in performance requirements. HTOC should additionally consider influencing human performance factors including cognitive, physical, skill and knowledge, cost of training for additional capability, cost of retain specific level of human performance mandated by program management, human errors, risk and uncertainty, technology development, environment factor (i.e. system readiness and work domain).

According to economic models, cost benefit analysis can reflect the human performance and learning curve in term of cost of investment, and risk-cost tradeoff analysis can illustrate the tradeoff between cost of technology and human performance. We have illustrated the preliminary regression model of HTOC which considers the human factor aspect, human reliability, and technology and environment factors. 
However, the major limitation is the lack of database in term of quantitative data and metrics associated with these factors is still questionable. Therefore, there are no specific economic models that can quantify the human soft cost drivers (subjective components) such as human factors aspects (cognition, physical, perceptual, skill and knowledge). Since the HTOC has involved within various variables and high degree of complexity, the preliminary model may not be the universal model to implement all organization needs. Instead, the multi-regression model can be conducted upon organization objectives. The models are also still questionable in validity, reliability and generalizability.

In future research, we will attempt to define the conceptual framework of human total ownership cost components, HTOC metric and measurement in quantitative terms. The preliminary HTOC model and cost-trade off analysis or cost and benefit analysis may be appropriate approach for designing technological works system.

\section{ACKNOWLEDGEMENTS}

This research was sponsored by the Office of $\mathrm{Na}$ val Research Contract No. N000141010835. The authors acknowledge the helpful guidance by ONR Program Management, and the contributions of the technical team.

\section{References}

[1] T. Z. Ahram and Waldemar Karwowski, "Human Systems Integration Modeling," in 53rd Annual Meeting of the Human Factors and Ergonomics Society (HFES 2009), San Antonio, Texas, USA, 2009.

[2] E. F. Hitt, "Total Ownership Cost use in Management," in Digital Avionics Systems Conference, 1998. Proceedings 17th DASC, Bellevue, WA, USA, 1998, pp. A32-1-5, Vol.1.

[3] M. W Boudreau and B.R. Naegle, "Total Ownership Cost Considerations in Key Performance Parameters and Beyond," Defense Acquisition Review Journal, pp. 109-121, 2003.

[4] J. S. Gansler, Definition of total ownership cost (TOC), life cycle cost (LLC), and the responsibilities of program managers, November 13, 1998.

[5] A. Sloan, "A More Effective Process for Identifying and Quantifying Measurable Performance Improvements," in ISA TECH/EXPO Technology Update Conference Proceedings, Vol.422, Milford, Ohio, 2002, pp. 243-253.

[6] R. R. Hoffman, W. Zachary, J. Burns, M. Drillings, C.R. Hale, and M. Linegang, "Human Total Cost of Ownership: Measuring the Impact of Human Factors on System Engineering," in Proceedings of the Human Factors and Ergonomics Society 52nd Annual Meeting, New York, NY, USA, 2008, pp. 202205.
[7] T. Z Ahram and W. Karwowski, "Measuring Human System Integration Return on Investment," in The International Council On Systems Engineering-INCOSE Spring 09 Conference: Virginia Modeling, Analysis and Simulation Center (VMASC), Suffolk, VA. USA, 2009.

[8] R.R. Hoffman, P. Hancock, and M. Marx, "Metrics, Metrics, Metrics: Negative Hedonicity," IEEE Intelligent Systems, Vol.23, No.2, pp. 69-73, 2008.

[9] S. Sackmann, E. Flamholz, and M. Bullen, "Human resource accounting: A state of the art review," Journal of Accounting Literature, Vol.8, No.235, pp. 235-264, 1989.

[10]N. Bontis, N.C. Dragonetti, K. Jacobsen, and G. Roos, "The Knowledge Toolbox: A Review of the Tools Available To Measure and Manage Intangible Resources," European Management Journal, Vol.17, No. 4, pp. 391-402, 1999.

[11] W. Zachary, K.Neville, and J. Fowlkes, "Human Total Cost of Ownership: The Penny Foolish Principle at Work," IEEE Intelligent Systems, Vol.22, No.2, pp. 88-92, 2007.

[12]P. Kopardekar and G. Hewitt, "Human Factors Program Cost Estimation-Potential Approaches: A Concept Paper," 2002.

[13] T. Whalen, "Economic value of intelligence," in Fuzzy Information Processing Society, 2009. NAFIPS 2009. Annual Meeting of the North American, 2009, pp. 14-17.

[14]J. Millhouse, "Leveraging Total Ownership Cost Analysis to Optimize In Service R\&M Programs," in 2009 The International Symposium on Product Quality and Integrity Proceedings, Fort Worth, TX, 2009, pp. 477-482.

[15]FAO/WHO(Food and Agriculture Orgainzation), Risk Characterization of microbiological hazard in food: Guidelines. Rome: Microbiological Risk Assessment Series No.17, 2009.

[16]A.E. Abbas and J.E. Matheson, "Normative Taget-Based Decision Making," Managerial and Decision Economics, Vol.26, pp. 373-385, 2005.

[17]C. A. Lengnick-hall and M. Lengnick-hall, "Strategic Human Resource Management: A Review fo the Literature and a Proposed Typology," Academy of Management Review, Vol.13, No.3, pp. 454-470, 1988.

[18] J. Fulop, "Introduction to Decision Making Methods," 2005.

[19] M. Kans and A. Ingwald, "Common database for costeffective improvement of maintenance performance," International journal of production economics, vol. 113, pp. 734-747, 2008. 